\section{A case of previously undiagnosed Crohn's disease presenting with acute pancreatitis as an extraintestinal manifes- tation}

To the editor: Although Crohn's disease $(\mathrm{CD})$ primarily involves the gastrointestinal tract, ${ }^{1}$ many extraintestinal manifestations such as eye, ${ }^{2}$ skin, ${ }^{3}$ hepatic and bile duct ${ }^{4}$ and locomotor system ${ }^{5}$ involvement may occur during the course of the disease. Patients with CD may develop acute pancreatitis due to several mechanisms, such as duodenal and/or bile duct involvement and drugs used to treat the disease..$^{6-8}$ Rarely, acute pancreatitis may appear as an extraintestinal manifestation of CD. ${ }^{7,9}$ We report a case of CD with a rare extraintestinal manifestation.

A 32-year-old male was admitted to clinic with abdominal pain and bloody diarrhea. The patient had been well until 5 years earlier when he began to experience recurrent diarrhea and abdominal pain. He had been seen at many centers for these complaints but no specific disease had been diagnosed. The abdominal pain had colicky character that aggravated with meals and was accompanied by nausea and vomiting. Ten days before admission, the abdominal pain had become more severe, radiating to his back and accompanied by severe nausea and vomiting, unlike previous periumbilical and epigastric pain. No drug abuse or alcohol consumption were noted.

Abdominal examination showed mild to moderate epigastric tenderness without guarding and rebound. Rectal examination was normal. Laboratory values included a white blood cell count of $10 \mathrm{200} / \mathrm{mm}^{3}$, hematocrit of $36.3 \%$, hemoglobin of $11.9 \mathrm{~g} / \mathrm{dL}$, erythrocyte sedimentation rate of $38 \mathrm{~mm} / \mathrm{h}, \mathrm{C}$-reactive protein of $29.8 \mathrm{mg} / \mathrm{dL}(0-8 \mathrm{mg} / \mathrm{dL}$, normal limit), and serum amylase of 390 U/L (25-125 U/L normal limit). Ultrasonography and computed tomography of the abdomen showed edematous pancreatitis. Histology of biopsies obtained from the stomach, terminal ileum and colon revealed patchy acute inflammation, abscess formation, lymphoid aggregates, granulomas with multinuclear giant cells surrounded by a lymphocytic rim in the lamina propria. Neither caseification necrosis nor foreign material was noted in the granulomas.

Gastric and iliocolonic CD accompanied with acute edematous pancreatitis was diagnosed on the basis of clinical, laboratory, endoscopic and histopatologic findings. After admission to clinic, the patient was treated as a case of acute pancreatitis. Subsequent radiologic and laboratory examination showed resolution of the pancreatitis in 10 days. Fifteen days after admission, magnetic resonance cholangiopancreaticography was performed and no pathology was detected in the pancreas and biliary tree. After resolution of pancreatitis, and after Entomoeba histolytica infection and tuberculosis were ruled out, high dose $(1 \mathrm{mg} / \mathrm{kg} / \mathrm{d})$ methylprednisolone therapy combined with mesalamine was started because of persistent diarrhea. All clinical and laboratory parameters were normal after 1 month of therapy. Mesalamine was continued at the same dose. The patient had no complaints in the following 6 months and gained $8 \mathrm{~kg}$.

An increase in reported cases of pancreatitis in patients with $\mathrm{CD}$ is highly suggestive of their association. ${ }^{10}$ Acute pancreatitis complicating CD may be idiopathic, related to biliary lithiasis, biliary tract involvement with $\mathrm{CD}$, duodenal CD, sclerosing cholangitis associated with inflammatory bowel disease or drugs used in the treatment of these patients, such as azathioprine, mesalamine, 6-mercaptopurine, corticosteroids and lipid emulsions. ${ }^{6,11,12}$ In many cases, no etiologic factors were found except for CD itself, indicating pancreatitis as an extraintestinal complication of CD. ${ }^{9}$

In our case, all etiologic factors, such as biliary tract disease, alcohol consumption, drug intake, metabolic causes and trauma, which may involved in the pathogenesis of acute pancreatitis, were ruled out. The patient was diagnosed with $\mathrm{CD}$ on the basis of clinical, laboratory, endoscopic and histopathologic findings at the follow up. Exclusion of biliary tract and duodenal involvement of $\mathrm{CD}$ and the other etiologic factors of acute pancreatitis suggested that acute pancreatitis developed in this case as an extraintestinal manifestation of CD. In the literature, it is emphasized that pancreatitis without Crohn's involvement of the duodenum, drugs, or other known etiological factors, suggests its role as an extraintestinal manifestation of $\mathrm{CD}^{7,9}$. In conclusion, acute pancreatitis may complicate CD either secondary to other well known etiologies or as an $\mathrm{ex}^{-}$ traintestinal manifestation. The treatment modality depends on 
the etiology. Therefore, it is very important to clarify the causative factor in these patients.

F. Fusun Bolukbas, MD.

Cengiz Bolukbas, MD

Mehmet Horoz, MD

Fusun Baba, MD

Ali Uzunkoy, MD

Yenisehir mah. 4. sok. Altiparmak apt. Kat.2 Daire 3

63100Yenisehir/ SanliurfaTurkey

E-mail: fusunbol@yahoo.ca

\section{References}

1. Farmer RG, Hawk WA, Turnbull RB Jr. Clinica patterns in Crohn's disease: A statistical study of 615 cases. Gastroenterology. 1975; 68: 627-635.

2. Hopkins DJ, Horan E, Burton IL, Clamp SE, de Dombal FT, Goligher JC. Ocular disorders in a series of 332 patients with Crohn's disease. $\mathbf{B r} \mathbf{J}$ Ophthalmol. 1974; 58: 732-737

3. Thornton JR, Teague RH, Low-Beer TS, Read AE. Pyoderma gangrenosum and ulcerative colitis. Gut.1980; 21: 247-248.

4. Cooperman AM, Judd ES. The role of colectomy in hepatic disease accompanying ulcerative and granulomatous colitis. Current status of a continuing problem. Mayo Clin Proc. 1972; 47 36-38.

5. Haslock I, Wright V. Musculoskeletal complications of Crohn's disease. Medicine (Baltimore). 1973; 52: 217-222

6. Weber P, Seibold F, Jenss H. Acute pancreatitis in Crohn's Disease. J Clin Gastroenterol. 1993; 17: 286-291.

7. Eisner TD, Goldman IS, McKinley MJ. Crohn's disease and pancreatitis. Am J Gastroenterol. 1993; 88: 583-586.

8. Salvarani C, Vlachonikolis IG, van der Heijde DM, et al. European Collaborative IBD Study Group. Musculoskeletal manifestations in a population-based cohort of inflammatory bowe disease patients. Scand J Gastroenterol. 2001; 36 1307-1313.

9. Gotian A, Katz S. Pancreatitis associated with Crohn's disease: A premalignant state for cystadenocarcinoma of pancreas? Am J Gastroenterol. 1999; 94: 2301-2302.

10. Papanikolaou IS, Liatsos C, Dourakis SS Mavrogiannis C. A case of acute pancreatitis associated with Crohn's disease. Ann Saudi Med. 2002; 22: 70-72

11. Decocq G, Gras-Champel V, Vrolant-Mille C, et al. Acute pancreatitis induced by drugs derived from 5-aminosalicylic acid: Case report and review of the literature. Therapie. 1999; 54:41-48.

12. Tragnone A, Bazzocchi G, Aversa G, et al Acute pancreatitis after azathioprine treatment for ulcerative colitis. Ital J Gastroenterol. 1996 28: 102-104. 